\title{
Diagnosis of Female Genital Tuherculosis by Means of Hysterosalpingography. Especially on the Clinico-Pathological Figures and Progress of Such Disease
}

I. Observation of Consecutive 192 Cases of Genital Tuberculosis

\author{
By \\ Ryuji Yamaguchi \\ (山口 龍二) \\ From the Department of Obstetrics and Gynecology, Faculty \\ of Medicine, Tohoku University, Sendai; \\ Director: Prof. K. Kushima
}

(Received for publication, April 14, 1959)

For diagnosis of tuberculosis of the female genitals by findings on hysterosalpingographs (referred to hereunder as HSG), Shinoda ${ }^{1)}$ and Takahashi $^{2)}$ in Japan and Rozin ${ }^{3)}$ in Europe have laid down classifications of the shadows specific to tuberculosis, but few have studied the development of the disease employing HSG, Ekengren \& Rydén's report ${ }^{4)}$ being the only one published recently. The present author will report hereunder the pathological findings and development of tuberculosis obtained in our detailed studies of HSG of tuberculosis cases.

\section{Subjects}

192 cases with tuberculosis of the genitals treated in 1950-1953 were examined. For confirmation of diagnosis, cultivation of tubercle bacilli from the genitals (from vaginal contents, menstrual blood, and uterine wash $\left.{ }^{8}\right)$ and histological examination of the endometrium and surgically extracted specimens were always applied. As contrast medium, $40 \%$ Molojodol (Lipiodol) was used and the roentgenograms taken 5-10 min. and 24 hours after the introduction of the contrast medium were chiefly used for fundamental study.

\section{Types and shadows examined}

The 28 types of shadows listed in Table I were examined.

Results

I. Relative frequency of the shadow. Types in the cases with and without genital tuberculosis 
TABLE I

Comparison of Appearance Rate of HSG Shadows in Tbc. and Non-Tbc. Group

\begin{tabular}{|c|c|c|c|}
\hline Group $\rightarrow$ & $\begin{array}{c}\text { Tbc. con- } \\
\text { firmed } 192 \text { cases }\end{array}$ & $\begin{array}{l}\text { Tbc. not con- } \\
\text { firmed, } 196\end{array}$ & \multirow[t]{2}{*}{ Ratio } \\
\hline Uterine shadaws & Out of 240 & Out of 199 & \\
\hline Normal uterine cavity & $80(33.3 \%)$ & $157(78.8 \%)$ & $1: 2$ \\
\hline Small uterus & $4(1.7 \%)$ & $3(1.4 \%)$ & $1: 1$ \\
\hline Enlarged uterus & $8(3.3 \%)$ & $5(2.4 \%)$ & $1: 1$ \\
\hline Tiny serration of uterine wall & $51(21.3 \%)$ & $4(2.0 \%)$ & $10: 1$ \\
\hline Rough serration of uterine wall & $10(4.2 \%)$ & $9(4.5 \%)$ & $1: 1$ \\
\hline Uterine angiogram & $28(11.7 \%)$ & $10(5.0 \%)$ & $2: 1$ \\
\hline Dilatation of internal os & $5(2.1 \%)$ & $2(1.0 \%)$ & $2: 1$ \\
\hline Deformation of uterine cavity & $27(11.3 \%)$ & $3(1.4 \%)$ & $9: 1$ \\
\hline Atrophy of uterine cavity & $22(9.2 \%)$ & $5(2.5 \%)$ & $4: 1$ \\
\hline Uterine relief & $5(2.1 \%)$ & $1(0.5 \%)$ & $4: 1$ \\
\hline Tubal shadows & Out of 619 & Out of 426 & \\
\hline Patent tube & $31(5.0 \%)$ & $195(45.8 \%)$ & $1: 9$ \\
\hline Low-patent tube & $7(1.2 \%)$ & $53(12.4 \%)$ & $1: 10$ \\
\hline Obstruction at uterine cornu & $101(16.3 \%)$ & $38(8.9 \%)$ & $2: 1$ \\
\hline Other simple obstruction & $18(2.9 \%)$ & $45(10.6 \%)$ & $1: 5$ \\
\hline Serration of ampulle & $56(9.0 \%)$ & $6(1.4 \%)$ & $7: 1$ \\
\hline Relief & $103(16.6 \%)$ & $21(4.9 \%)$ & $3: 1$ \\
\hline Stricture of ampulle & $13(2.1 \%)$ & $1(0.2 \%)$ & $10: 1$ \\
\hline Dilatation of ampulle and sactosalpinx & $39(6.3 \%)$ & $28(6.6 \%)$ & $1: 1$ \\
\hline Round sacculation & $60(9.7 \%)$ & $12(2.8 \%)$ & $4: 1$ \\
\hline Ragged isthmic shadow & $109(17.6 \%)$ & $4(0.9 \%)$ & $20: 1$ \\
\hline Dilatation of isthmus & $28(4.3 \%)$ & $4(0.9 \%)$ & $5: 1$ \\
\hline Dilatation of interstitial part & $20(3.2 \%)$ & $5(1.2 \%)$ & $3: 1$ \\
\hline Paratubal opaque invasion & $14(2.3 \%)$ & $5(1.2 \%)$ & $2: 1$ \\
\hline Peritubal relief & $6(1.0 \%)$ & $1(0.2 \%)$ & $5: 1$ \\
\hline Fimbrial shadow & $11(1.8 \%)$ & $0(1.9 \%)$ & $1: 1$ \\
\hline Calcification in tube & $3(0.5 \%)$ & $0 \quad-$ & - \\
\hline Pelvic shadows & Out of 192 & Out of 196 & \\
\hline Calcification in pelvic cavity & $21(10.9 \%)$ & $8(4.0 \%)$ & $2: 1$ \\
\hline Adhesion in pelvic cavity & $6(3.1 \%)$ & $7(3.5 \%)$ & $1: 1$ \\
\hline
\end{tabular}

Table I shows the rough ratios of the frequencies of the shadows appearing in the roentgenograms of 192 cases with confirmed tuberculosis of the genitals and of 196 cases blindly selected from 904 cases without proven genital tuberculosis as controls. It shows that tiny serrations of 


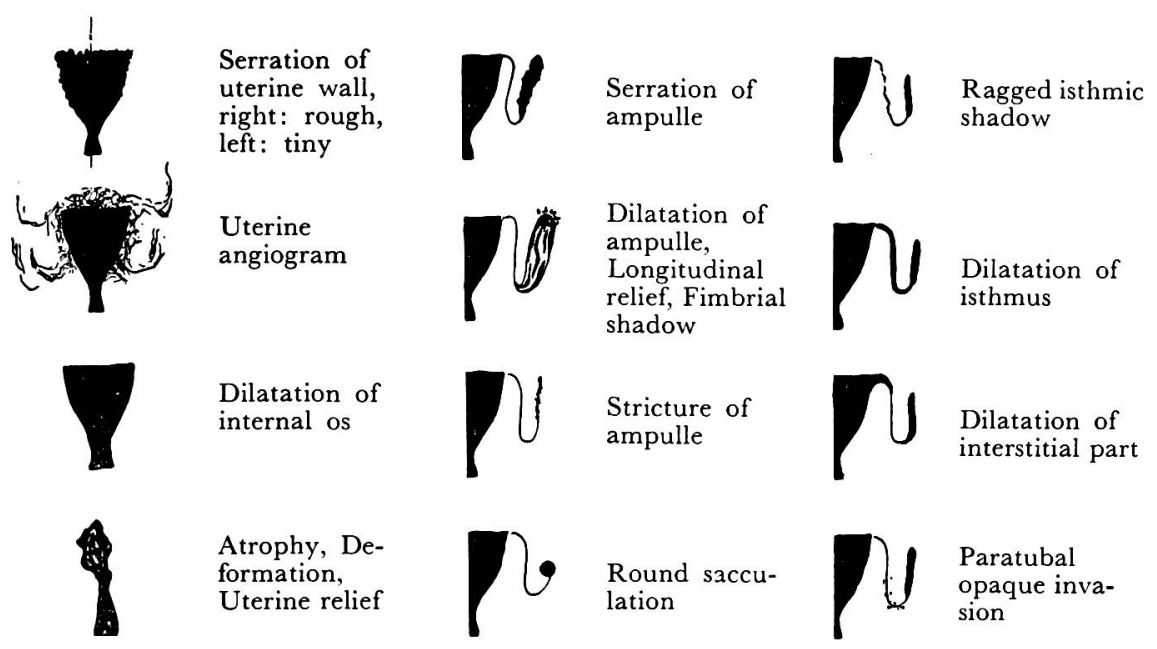

Fig. 1. Schema of Tuberculous Shadows.

the uterine wall, atrophy of the uterus, deformation of the uterine cavity, serration and stricture of the ampulla, serration of the isthmus (raggedwire-like shadow), round saccultion (cherry-like shadow), tubal relief and various calcification shadows may be deemed as indicative of tuberculosis with considerable reliability and also that uterine angiogram, dilatation of the isthmus, paratubal opaque invasion, and dilatation of the interstitial part are also much more frequent in tuberculous cases.

\section{Distribution of combinations of tuberculous shadows}

Counting every tuberculous shadow observed as 1 item and two shadows of the same type as 2 items, the distribution of the frequencies of more than one tuberculous shadows in coexistence was as shown in Table II. When the number of tuberculous-type shadows found in one individual case becomes large existence of tuberculosis becomes the more probable, and when 5 or more tuberculous shadows coexist, diagnosis of tuberculosis becomes well-high infullible.

TABLE II

Distribution of Combination Number of "Tbc. Shadows"

\begin{tabular}{l|rrrrrrrrrr}
\hline \multicolumn{1}{c|}{ Combination No. } & 0 & 1 & 2 & 3 & 4 & 5 & 6 & 7 & 8 & 9 \\
\hline Tbc. not confirmed, 196 cases & 129 & 31 & 17 & 14 & 5 & 1 & 1 & 0 & 0 & 0 \\
Tbc. confirmed, 192 cases & 17 & 21 & 35 & 36 & 24 & 24 & 15 & 10 & 6 & 3
\end{tabular}

III. Classification and correlation of the HSG findings in tuberculosis

As previously reported by the present author ${ }^{910)}$, the cases of female 
genital tuberculosis can be classified into the following three major groups based upon HSG findings: Group I showing perceptible change in neither the uterus nor the fallopian tubes and with the tubal patency intact, Group II with various tubal changes but not marked uterine change and Group III with advanced changes in the uterus too. The salpingographic findings are apparently classifiable into two representative types again: Type A with changes more notable in the ampulla and Type B with changes more notable in the isthmus. The above classifications will be referred to hereunder in studying how they match with the development of genital tuberculosis.

1. Change in Various Shadows; As seen in Table III, a peculier change in the ratios of the various shadow types appears when we go over from Group I to Group II. The correlation between the changes in the uterus and the several representative types of tubal changes in combination was as shown in Table IV.

TABLE III

Three Group Classification and Shadow Transition

\begin{tabular}{|c|c|c|c|}
\hline Tbc. shadow $\downarrow \quad$ HSG group $\rightarrow$ & I (15 cases $)$ & II (131 cases) & III (39 cases) \\
\hline Patent tube & $13<\begin{array}{lr}\text { both } & 12 \\
\text { one } & 1\end{array}$ & $4<\begin{array}{l}\text { both } \\
\text { one }\end{array}$ & 0 \\
\hline Low patent tube & $2<$ bothe & $3<\begin{array}{l}\text { both } \\
\text { one }\end{array}$ & 0 \\
\hline Obstruction at uterine cornu & 0 & $45<$ one & $25<$ one \\
\hline Tbc. tubal shadow Type-A & $4<\begin{array}{l}\text { both } \\
\text { one }\end{array}$ & $37<$ one & $1<$ both \\
\hline Tbc. tubal shadow Type-B & 0 & $\begin{array}{ll}56<\text { both } & 33 \\
\text { one } & 23\end{array}$ & $18<\begin{array}{lr}\text { both } & 10 \\
\text { one } & 8\end{array}$ \\
\hline Tbc. uterine shadow & $3<\begin{array}{ll}\text { slight } & 3 \\
\text { manifest } & 0\end{array}$ & 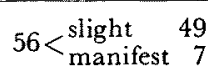 & $39<\begin{array}{l}\text { slight } \\
\text { manifest } \\
38\end{array}$ \\
\hline Calcification in pelvic cavity & 0 & $11(8.4 \%)$ & $10(25.6 \%)$ \\
\hline Adhesion in pelvic cavity & 1 & 4 & 0 \\
\hline Culture positive cases & 14 & 98 & 33 \\
\hline Average of colony (Median) & 1.5 & 2.5 & 4.0 \\
\hline
\end{tabular}

* 7 cases which are difficult to classfy are excluded

From these findings, we might reasonably conclude that 1) tubal obstruction does not suddenly arise at the uterine cornu but develop from the ampulla to the cornu, 2) the decrease of A type tubal shadows with 
T A B LE IV

Relation between Uterine and Tubal Changes

\begin{tabular}{|c|c|c|c|}
\hline $\begin{array}{ll}\text { Tubal } & \begin{array}{l}\text { Intensity of ut. } \\
\text { change (case) } \rightarrow\end{array} \\
\text { shadow } \downarrow & \end{array}$ & $\begin{array}{l}\text { Normal ut. } \\
\text { shadow (80) }\end{array}$ & $\begin{array}{l}\text { Tiny serration } \\
\text { of ut. wall ( } 30)\end{array}$ & $\begin{array}{l}\text { Other tbc. ut. } \\
\text { shadow with tiny } \\
\text { serration }(60)\end{array}$ \\
\hline $\begin{array}{l}\text { Serration of ampulle } \\
\text { Tubal relief } \\
\text { Dilatation of ampulle }\end{array}$ & $\begin{array}{r}11.7 \% \\
25.5 \% \\
6.7 \%\end{array}$ & $\begin{array}{r}11.4 \% \\
19.1 \% \\
8.4 \%\end{array}$ & $\begin{array}{l}6.0 \% \\
4.5 \% \\
2.8 \%\end{array}$ \\
\hline $\begin{array}{l}\text { Ragged isthmic shadow } \\
\text { Round sacculation }\end{array}$ & $\begin{array}{l}14.4 \% \\
11.4 \%\end{array}$ & $\begin{array}{l}25.7 \% \\
11.9 \%\end{array}$ & $\begin{array}{l}28.8 \% \\
10.6 \%\end{array}$ \\
\hline Obstruction at ut. cornu & $7.4 \%$ & $8.9 \%$ & $40.2 \%$ \\
\hline Patent tube & $7.7 \%$ & $2.9 \%$ & 0 \\
\hline Other tubal shadows & $16.2 \%$ & $11.7 \%$ & $7.1 \%$ \\
\hline
\end{tabular}

the increase of uterine changes is partly attributable to the progress of tubal obstruction but 3) partly suggests that Type B changes are older in time than Type A changes. The gradual increase in frequency of calcification shadows in the pelvic cavity from Group I to Group III shows that the latter is the oldest in age.

2. Bacillous discharge in the three groups

As shown in Table III, the cultivation tests showed nearly always positive results in Group I, because the cases of this group can be seldom detected except by bacillar cultivation. In Group II and III too, positive cases were more frequent but negative cases were not at all rare, and in particular, Group II included about one-fourth of negative cases. Such negative results have been hitherto attributed to defects in cultivation or effects of the menstrual cycle, but we were inclined to infer existence of closed type in genital tuberculosis as in tuberculosis of other sites, and studying the factors leading to such negative bacillus discharge on HSG, arrived at the results in Tables V, VI and VII.

TABLE V

Results of Culture of Vaginal Tbc. Bacilli and HSG Changes of Tubes and Uteri in 2nd Group of HSG (93 Cases)

\begin{tabular}{c||c|c|c|c}
\hline \multicolumn{2}{c|}{ HSG $\rightarrow$} & \multicolumn{2}{c|}{ Tbc. involved uteri } & \multicolumn{2}{c}{ Not involved uteri } \\
\cline { 2 - 5 } Culture $\downarrow$ & $\begin{array}{c}\text { Tubal } \\
\text { shadow-A }\end{array}$ & $\begin{array}{c}\text { Tubal } \\
\text { shadow-B }\end{array}$ & $\begin{array}{c}\text { Tubal } \\
\text { shadow-A }\end{array}$ & $\begin{array}{c}\text { Tubal } \\
\text { shadow-B }\end{array}$ \\
\hline Positive culture & 8 & 22 & 21 & 21 \\
Negative culture & 3 & 4 & 5 & 9 \\
\hline Total & 11 & 26 & 26 & 30
\end{tabular}




\section{TABLE VI}

Results of Culture of Vaginal Tbc. Bacilli in The ViewPoint of Menstrual Cycle and Uterine and Tubal Changes in Second Group of HSG (23 Cases)

\begin{tabular}{l|c|c|c|c|c|c}
\hline & \multicolumn{2}{|c|}{$\begin{array}{c}\text { With tiny serration of } \\
\text { uterine wall }\end{array}$} & $\begin{array}{c}\text { Without tiny serra- } \\
\text { tion of uterine wall }\end{array}$ \\
\hline & $\begin{array}{c}\text { Tubal shadow } \\
\text { type-A }\end{array}$ & B & A + B & A & B & A+B \\
\hline $\begin{array}{c}\text { Positive culture only at premenstrual } \\
\text { and menstrual stadium } \\
\text { Positive culture throughout menstrual } \\
\text { cycle }\end{array}$ & 3 & 3 & 1 & 2 & 5 & 1 \\
& 2 & 2 & 1 & 2 & 0 & 1
\end{tabular}

TABLE VII

Results of Culture of Vaginal Tbc. Bacilli and Intensity of Uterine Involvement in Third Group of HSG (39 Cases)

\begin{tabular}{l|r|r|c|c}
\hline & \multicolumn{3}{|c|}{ Positive culture } & \multirow{2}{*}{ Negative culture } \\
\cline { 2 - 4 } & & \multicolumn{2}{|c|}{ Average of colony } & \multirow{2}{*}{ Total } \\
\cline { 2 - 3 } & & Over 3 & Under 3 & \\
\hline Marked destroyed & 15 & 11 & 4 & 3 \\
Not so destroyed & 11 & 6 & 5 & 2 \\
Atrophied or deformed & 7 & 1 & 6 & 1
\end{tabular}

As factors affecting the discharge of bacilli in the vagina, we may find 1) the menstrual cycle, as already pointed out in the past, 2) grade of uterine involvement and 3) the findings of the fallopian tubes. As shown in Table V, in Group II of cases almost all free of menstrual anomalies, the discharge of bacilli is seen to be influenced by the presence of anomalies in the uterus, especially, of tiny serrations in the uterine wall, and among the cases free of uterine anomalies, as shown in Table VI, positive cultures are found more frequent among the cases with Type A tubal pictures than those with Type B tubal pictures, both just before menstruation and in the intermenstrual periods. In the Group III of cases with various anomalies in the uterus, as shown in Table VII, the severity of such uterine changes influences both the frequency of positive cases and the quantity of the bacilli in the culture, but in the case the uterine anomalies chiefly consist in its atrophy or deformation, the bacillus discharge is low. From this, we conclude that the Group III may be subdivided into Type A cases with minute serrations or angiograms and Type B cases with uterine atrophy or deformation chiefly appearing on their HSG. Now, as 17 of 
the 39 cases in Group III were amenorrheic and the majority of the others hypomenorrheic, it may be presumed that the influence of the menstrual cycle was scarcely felt in the figures in Table VII.

IV. Tiny serrations in the uterine wall

Of all the uterine findings in tuberculosis of female genital organs tiny serrations in the uterine wall are the most fundamental and were found in $25 \%$ of our tuberculous cases. Upon closer examination of these serrations, they were found particularly frequent in the fundus of the uterus (Table VIII).

TABLE VIII

Tiny Serration of Uterine Wall

\begin{tabular}{l|c|c|c|c|c}
\hline & $\begin{array}{c}\text { Fundal } \\
\text { serration } \\
\text { alone }\end{array}$ & $\begin{array}{c}\text { Fund. serr. } \\
\text { intensive, cor- } \\
\text { poral serration } \\
\text { slight }\end{array}$ & $\begin{array}{c}\text { Corporal } \\
\text { serr. } \\
\text { alone }\end{array}$ & $\begin{array}{c}\text { Corp. serr. } \\
\text { intensive, } \\
\text { fund. serr. } \\
\text { slight }\end{array}$ & $\begin{array}{c}\text { Serr. of } \\
\text { all ut. } \\
\text { wall }\end{array}$ \\
\hline $\begin{array}{c}\text { With other uterine } \\
\text { shadows } \\
\begin{array}{c}\text { Without other uterine } \\
\text { shadows }\end{array}\end{array}$ & $2(10.5 \%)$ & $1(5.2 \%)$ & 0 & 0 & $16(84.3 \%)$ \\
$10(23.3 \%)$ & $12(27.9 \%)$ & $6(13.9 \%)$ & $1(2.3 \%)$ & $14(32.6 \%)$
\end{tabular}

From this, it may be inferred that the fundamentalmost type of such uterine serrations is those in the fundus uteri, and very probably such fundal serrations are the incipient type of all endometrial serrations. Clinically speaking, we may recommend to select the fundus in diagnostic endometrial curettage as the most promissing point of attack.

\section{SUMmary}

Since methods for successful cultivation of tubercle bacilli from genital organs were established more than a dozen years ago (Shinoda \& Iwabuchi $^{5)}$, 1941 ; Furuhashi ${ }^{6)}$, 1947; Halbrecht ${ }^{7)}$, 1947; Yamaguchi ${ }^{8}$, 1952), studies on genital tuberculosis have been encouraged and minute schedules of classification of tuberculous findings based on HSG have been undertaken by Shinoda \& Takahashi ${ }^{2)}$ (1943), Kika, Yamaguchi, et al. ${ }^{9-12 \text { ) }}$ (1951) in Japan and noteworthy reports on the subjects have appeared in Europe too, of Magnusson ${ }^{14)}(1945,1947)$, Rozin $^{3)}(1952,1954)$, Ekengren \& Rydén ${ }^{4)}$ (1952) and some others ${ }^{15116) 17) .}$

On the correlation, however, between the different types of tuberculous HSG shadows, their combination and the relation of the findings to discharge of tubercle bacilli we have no report available to date. We have once discussed the pathological pictures and development of genital tuberculosis classifying the cases with the disease into three groups with consideration to the results of cultivation of tubercle bacilli and endometrial 
biopsy (Kika, Yamaguchi, et al. ${ }^{9)}, 1952$ ) and in the present paper, have described the existence of Type A and B among the representative types of tubal findings on HSG, discovered in our closer examination of the HSG of tuberculous cases. From considerations on some relavant findings, we are led to conclude that the Type A findings are younger than the Type B findings and it seems the former develops eventually into the latter. The fundamental type of uterine findings was inferred to consist in the tiny serrations in the uterine walls, which first arise in the fundus near the uterine cornu and gradually spread all over the uterine wall.

These has been no report on the development of genital tuberculosis studied from the angle of HSG findings, except that by Ekengren \& Rydén $^{4)}$ (1950) on the progress of tubal tuberculosis. Their results are in rather good agreement with the ours, but we must state with regret that they failed to study the subject from the bacteriological angle and to review the results in comprehensive discussion with the uterine and the pelvic roentgenographic findings. Our study, we hope, my serve in supplementing some of the shortcomings of their studies.

\section{Conclusions}

1. The HSG of 192 cases with genital tuberculosis encountered in these 4 years were examined thoroughly, to discuss the pathological findings and development of the disease.

2. In divergence from the opinion accepted hitherto, we found the diagnostic accuracy obtained by examination of HSG in genital tuberculosis cases is very high, if we take the number of tuberculous findings in coexistence and the combination types of such findings into account.

3. The outstanding combination types of findings in tubal tuberculosis can be classified into the Type A represented by serration in the ampulla and tubal relief and Type B represented by raggedness of the isthmus and round saccultion (cherry-like shadows). Many findings led us to conclude that the Type A temporally precedes Type B.

4. Among the tuberculous uterine findings, tiny serrations in the uterine wall were found the fundamental anomalies. These arise in the fundus and thence gradually spread all over the uterine wall. The uterine anomalies too can be classified in considerations on the results of cultivation of bacilli etc. into Type A with serration and angiograms as the main findings and Type $B$ represented by atrophy and deformation of the uterus. Here, Type A seems to represent the fresher changes than Type B.

\section{References}

1) Shinoda \& Takemura, Rinshio Igaku (Jap.) 1940, 27, 39.

2) Takahashi, Tohoku Igaku Zasshi (Jap.), 1943, 32, 639. 
3) Rozin, J. Obstet. Gynaec. Brit. Emp. 1952, 69, 59 ; Fertil \& Steril., 1954, 5, 468.

4) Ekengren \& Rydén, Acta radiol., 1950, 34, 193 ; ibid., 1952, 36, 485.

5) Shinoda \& Iwabuchi, Tohoku Igaku Zasshi (Jap.), 1941, 28, 923.

6) Furuhashi, ibid., 1949, 39, 93.

7) Halbrecht, J.A.M.A., 1949, 142, 331 ; Lancet, 1947, 2, 947.

8) Yamaguchi, J. Jap. Obstet. Gynec. Soc., 1954, 1, 129.

9) Kika, Yamaguchi, Kimura, Narita, Shimada \& Wakabayashi, Sanka-To-Fujinka (Jap.), 1952, 19, 288.

10) Kika, Yamaguchi, Shimada, Wakabayashi \& Kubo, Nippon Sanka-Fujinka Gakkai Zasshi (Jap.), 1952, 4, 1020.

11) Kika, ibid., 1956, 8, 495.

12) Kubo, ibid., 1956, 8, 1485.

13) Eguchi, ibid., 1957, 9, 71.

14) Magnusson, Acta radiol., 1945, 26, 265 ; ibid., 1947, 28, 824.

15) Madsen, ibid., 1947, 28, 812.

16) Ko-Chi-Sun, Am. J. Obst. \& Gyn., 1948, 55, 953.

17) Marsalek, Gynaecologia, 1953, 135, 37.

18) Kan, Nippon Sanka-Fujinka Gakkai Zasshi (Jap.), 1957, 7, 481.

19) Miyano, ibid., 1957, 7, 589. 

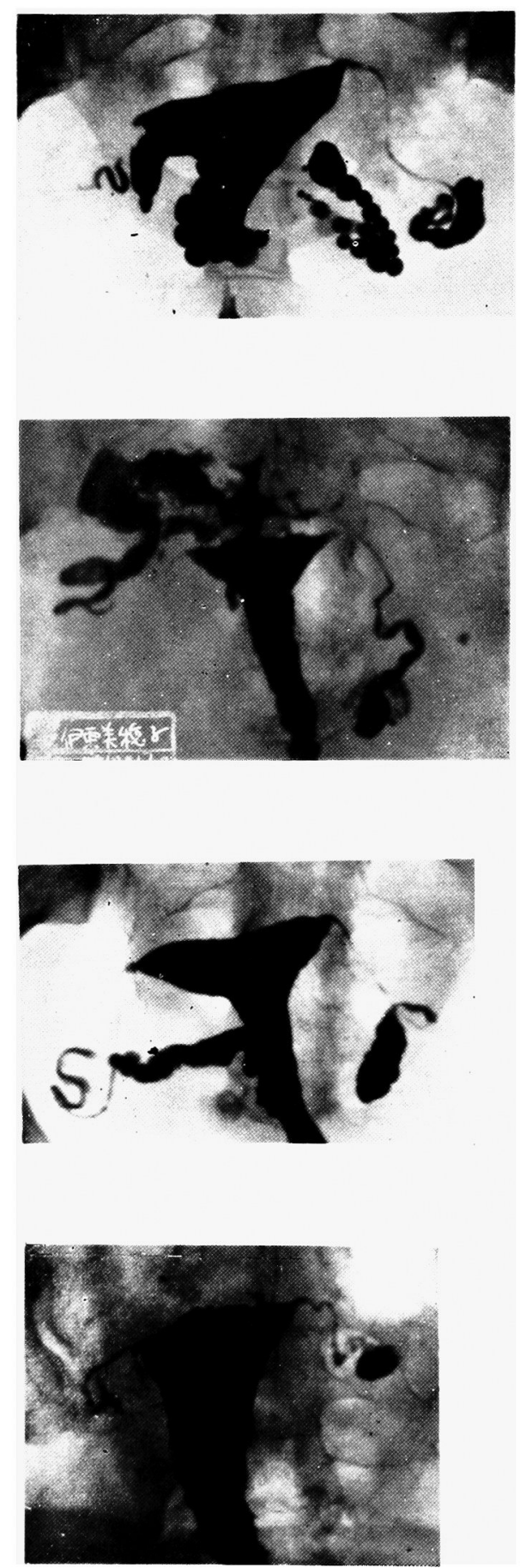

Fig. 2-a. (B-2334)

HSG classification group.

I-A : No pathological change.

Fig. 2-b. (B-2061)

I-B : Tubal patency is still maintained, but slight change of tubes is alreadly seen, especially in the left side.

Fig. 3-a. (B-2185)

II-A : Distinct ampullar findings are visible (Serration, dilatation and relief) but the isthmus and the uterus are normal.

Fig. 3-b. (B-2995)

II-B : Excessive changes of isthmus (ragged isthmic shadow, round sacculation), and serration of uterine wall and dilatation of internal os are also present. 
Fig. 4-a. (B-2291)

III-A : Typical uterine angiogram.

Fig. 4-b. (B-3249)

III-B : Deformation and atrophy of uterus with slight uterine angiogram.
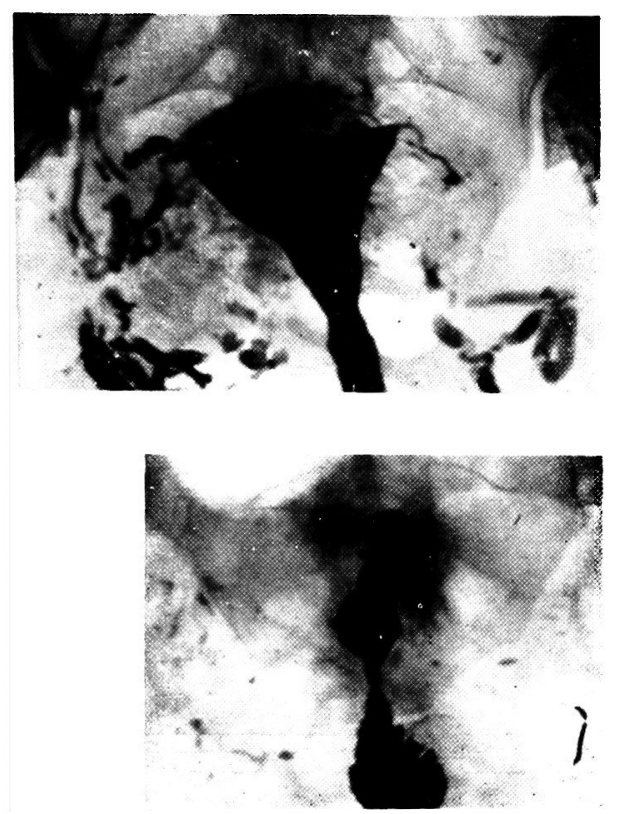